\title{
Prejudice, Tolerance, and Attitudes toward Ethnic Groups
}

\author{
MARY R. JACKMAN \\ University of Michigan
}

\begin{abstract}
This paper presents a conceptual and empirical examination of the term "prejudice." Beginning with a discussion of the cognitive, affective, and conative dimensions of an inter-ethnic attitude, it is argued that the conceptual distinctions among the three attitudinal components are sufficient to question the utility of the blanket description "prejudiced." This is followed by an exploratory analysis of data on the affective and conative dimensions of attitude toward blacks from a national public opinion survey. Scales tapping affective feelings and two different types of action orientation toward blacks are successfully isolated. Relationships among the scales are moderate and are influenced by variables tapping regional norms and attitudinal intensity. The paper concludes with a brief discussion of the term "tolerance"' as it has developed in political sociology (that is, as a specific attitude structure whereby competing groups maintain a positive action orientation toward one another in spite of openly conflicting values or interests) and suggests the application of this concept to the study of inter-ethnic attitudes. Empirical analysis of the structure of inter-ethnic attitudes, including "tolerant" attitude structures, would facilitate an integration of the theoretical and policy concerns of the ethnic attitudes literature with those of political sociology.
\end{abstract}

The self-evident and pressing social issue posed by negative attitudes toward ethnic groups (and especially toward blacks) in the United States has been the subject of considerable research, and the terms "prejudice" and "tolerance" have occupied an important place in sociology. However, while these terms have been used frequently in empirical studies of inter-ethnic attitudes, the exact empirical referent for each of them often varies across studies. To add further confusion, the term "tolerant" has often been used in a general way in the literature on inter-ethnic attitudes to describe someone who is "not prejudiced" (see, e.g., Allport, 1958, pp. 398-401; Bettelheim and Janowitz, 1965, p. 686; Frenkel-Brunswik et al., 1965, p. 679), while the literature on democratic theory in political sociology reserves the term to describe an individual who adheres to specific democratic principles-the principles of majority rule and mi-

I would like to thank Warren O. Hagstrom, Robert W. Jackman, Russell Middleton, Howard Schuman, William H. Sewell, and Gene F. Summers for their helpful comments on earlier drafts of this paper. The research was supported in part by the Graduate Research Committee at the University of Wisconsin, Madison, and a Faculty Summer Fellowship from the Horace H. Rackham School of Graduate Studies at the University of Michigan. The data were kindly made available by the Inter-University Consortium for Political Research. Address for reprints: Department of Sociology, University of Michigan, Ann Arbor, Michigan 48104. 
nority rights, whereby competing (dominant and subordinate) groups in society accommodate one another in spite of openly conflicting goals and interests (see, e.g., Stouffer, 1955).

This paper presents a conceptual and empirical exploration of the structure of an inter-ethnic attitude. ${ }^{1}$ The central contention is that the term "prejudice" should be abandoned in favor of empirical treatment of an inter-ethnic attitude as a complex, multidimensional phenomenon that cannot be summarized or described by a single term or measure. Such a step might not only help to clarify conceptual and empirical issues in the literature on inter-ethnic attitudes, but would also help integrate that literature with the complementary concern of political sociology over the problem of peaceful multigroup coexistence in a democratic society.

The literature in psychology and social psychology presents a plethora of definitions of the term "attitude," but most approaches agree that an attitude comprises three elements: (a) a cognitive or belief component, (b) an affective or emotive component, and (c) a conative or behaviororientation component (Katz and Stotland, 1959; Krech et al., 1962; Cook and Selltiz, 1964; Greenwald, 1968, p. 363; Summers, 1970, p. 2). Following this framework, a "prejudiced" attitude is also generally considered to have three aspects: (a) a set of negative, generalized beliefs, or "stereotypes," about an ethnic group, (b) a feeling of dislike for the group, and (c) a predisposition to behave in a negative way toward the group, both in personal face-to-face situations and in orientation toward social customs and political policies that affect the well-being of the object group (Harding et al., 1968, p. 4).

However, while this conceptualization of a prejudiced attitude as comprising three elements has become widely accepted on the theoretical level, it has typically not been reflected in empirical measures of the concept. Many empirical studies of prejudice have relied on measures that reflect only one of the three components, while others have treated items tapping different components as empirically equivalent by combining them in a single scale [see, e.g., the studies reviewed by Robinson $e t$ al. (1968, pp. 203-278) and Middleton (1976)]. While, in many cases, such a gap between theoretical and empirical levels may be attributed to circumstances beyond the researcher's control (such as fragmentary data sources or limited budgets), several researchers have voiced doubts about the necessity of treating inter-ethnic attitudes as empirically multidimen-

${ }^{1}$ In this paper, an "inter-ethnic attitude" is defined as "an attitude which a person has toward some or all members of an ethnic group, provided that the attitude is influenced to some degree by knowledge (or presumed knuwledge) of the other individual's group membership" (Harding et al., 1968, p. 3). Also following Harding et al. (1968, p. 3), an "ethnic group" is defined as "a collection of people considered both by themselves and by other people to have in common one or more of the following characteristics: (1) religion, (2) racial origin (as indicated by readily identifiable physical features), (3) national origin, or (4) language and cultural traditions." 
sional phenomena. A recurring argument has been that the cognitive, affective, and conative components of an attitude can be distinguished clearly at a conceptual level only: At the empirical level, the three components are so closely related and tightly interwoven that it would be very difficult, if not impossible, to obtain a pure measure of each that was not bound up with the others (Harding et al., 1954, p. 1023; Greenwald, 1968, p. 378; Rokeach, 1968, p. 113; Selznick and Steinberg, 1969, p. 136). Harding et al. (1954) state further that:

The discrepancies in attitude occur often enough to make us quite sure that prejudice toward a particular group is not actually a unitary variable; however, the relationship among the various attitudinal components is so close that it does not make much difference in practice whether we use cognitive, affective, or conative tendencies to rank individuals with respect to their attitudes toward any specific ethnic group [see Rokeach, 1968, p. 113 for a reiteration of this argument]. (p. 1030)

This approach to inter-ethnic attitudes, which has facilitated the empirical portrayal of the problem as a single continuum ranging from "prejudiced" at one end to "unprejudiced" or "tolerant" at the other, is questioned in this paper. We begin with a discussion of the conceptual boundaries of each of the three components of an inter-ethnic attitude, ${ }^{2}$ following this with an illustrative empirical investigation of the relationship between two of them (the affective and action orientation components of respondents' attitudes toward blacks) with data from a national public opinion survey. The paper concludes by discussing the implications of this exploratory investigation for the concept of tolerance, as it has developed in political sociology, and its relevance to the problem of ethnic relations.

\section{COMPONENTS OF AN INTER-ETHNIC ATTITUDE}

\section{Beliefs}

Beliefs about an ethnic group have perhaps been used independently more often than either of the other two conceptual dimensions of an attitude to indicate antipathy toward an ethnic group. Beliefs are usually measured by recording a person's response to a series of items of the general form "blacks are lazy," "Jews are aggressive," and so on. The characteristics attributed to ethnic groups in such items are generally of a stereotypical nature and thus it is sometimes assumed that, if a person agrees with these assertions, he has a negative attitude toward the group in question:

Anti-Semitic beliefs also have a distinctively emotive [as well as cognitive] component:

2 This discussion will not consider problems involved in obtaining a valid measure of a specific attitudinal element itself through various methods of item and scale construction and, instead, will be restricted to an assessment of the conceptual limitations of each attitudinal component, measurement problems aside. 
They are pejorative, derogatory, often hostile. Those who accept anti-Semitic stereotypes accept them as fact just as the superstitious accept their beliefs as fact. But facts have normative implications: The supcrstitious avoid black cats; anti-Semites avoid Jews. They do so because anti-Semitic beliefs, in addition to being statements of alleged fact, are reasons for disliking Jews. In learning anti-Semitic beliefs, the individual learns what is allegedly wrong with them [for a similar statement, see Allport. 1958, p. 13]. (Selznick and Steinberg, 1969, p. 13)

This assumption is questioned on three grounds.

First, it overlooks the difficulty that a particular belief does not take on negative connotations unless a negative value is associated with it. Thus, the belief that "Jews are aggressive" cannot be considered to be a negative belief unless we know that the individual holding the belief also adheres to the value that "aggressiveness" is an undesirable or unattractive quality (Rosenberg, 1956, p. 367; Fishbein, 1967, p. 479; Jones and Gerard, 1967, pp. 159-162; Doob, 1967, p. 491). If the individual actually rates aggressiveness as a desirable or even a neutral quality, he can hardly be considered an anti-Semite because he believes that Jews are aggressive.

A study by Kay (1947) asked Jewish and non-Jewish subjects to rate the positive/negative implications of 10 "anti-Semitism" items, of which 5 were belief items and 5 were action-orientation items: Her results indicate wide variation in ratings, with the individual's frame of reference playing an important role in his interpretation. Katz and Braly's (1947) aggregate-level analysis of 100 Princeton undergraduates found that the average affective ranking of 10 ethnic groups by one group of students correlated highly with an implied ranking of the groups based on the average-rated desirability by a second group of students of 84 traits that were used by a third group to describe each of the ethnic groups. Katz and Braly do not report individual variance in the rated desirability of each of the traits, but I suggest that, even for those traits eliciting a relatively high level of consensus about their desirability or undesirability, there would be a considerable margin of error involved in assuming that every individual attaches the same value to each trait.

A second reason for questioning the adequacy of measuring beliefs alone to tap inter-ethnic attitudes lies in the simple problem that some "negative beliefs" may be empirically true, or at least have an empirical basis. Schuman and Harding (1964) discuss this issue in terms of "rational" and "irrational" responses to belief items. They argue that, in some cases, the rational, or correct, response to a belief item may be unfavorable to the ethnic group in question and that responses may be classified as rational or irrational, as well as favorable or unfavorable, toward the object group [see Brigham (1971) and Mackie (1973) for lengthy discussions of the "kernel of truth" hypothesis].

An example of a statement that represents a simplification of empirical 
reality in the United States is that "Jews have more money than other people." While agreement with this statement has sometimes been assumed to be associated with a resentful attitude toward Jews, the fact remains that the average income level of Jews is relatively high. Table 1 indicates that, in a 1964 NORC survey of the United States, ${ }^{3}$ only $3.0 \%$ of those who believe that, "on the average, Jews have more money than most people" also responded positively to the question, "Some people have told us that it bothers them that Jews have more money than most people-Does it bother you at all?" The treatment of any generalized beliefs about an ethnic group as irrational and negative no doubt arose as a liberal response to dogmatic racist claims of inherent and immutable differences between ethnic groups. However, as Inkeles and Levinson (1969) point out, there may be true differences in "modal personality" between groups with varying structural and/or cultural origins, the assertion of which does not automatically imply that these differences are either immutable or undesirable.

A third reason for questioning the adequacy of beliefs as an indicator of an inter-ethnic attitude lies in the platitudinous nature of many beliefs about ethnic groups. Some stereotypical beliefs have such a platitudinous element that many respondents may adhere to them in an unthinking fashion with very little intellectual or emotional involvement. Schuman and Harding (1964) report from their data on the responses of Boston adults to forced-choice pairs of beliefs that there is a tendency, especially among those respondents with less education, to adhere to irrational beliefs both favorable and unfavorable to ethnic groups. They suggest that such individuals should not be classified as prejudiced since their beliefs are just taken-for-granted platitudes that have very low salience or relevance for either their affect or their behavior orientations.

The statement that "Jews have too much power in the business world" is a clear negative value judgment (the words "too much" make that unambiguous), but it is also an example of a platitudinous belief to which many people might adhere with little intellectual or emotional involvement. In our NORC sample, respondents were asked, "Do you think Jews have too much power in the business world?" Table 2 indicates that, of those who responded positively to this question, only $26.2 \%$ felt strongly enough about it to respond positively to the follow-up question, "Do you think something should be done to take some power away from the Jews?" This illustration is especially interesting since the power of

${ }^{3}$ The NORC sample is a modified probability (block quota) sample of the United States with quotas for age, sex, and female employment status at the block level. The use of block quotas makes significance tests strictly inappropriate with these data, but has little effect on the characteristics of the sample (Sudman, 1966). Primary analysis with this survey was completed by Selznick and Steinberg (1969), and more details on the characteristics of the survey may be obtained there. 
TABLE 1

Affective Feelings Toward Jews of Those Who Believe that "On the Average. Jews Have More Money than Most People."a

\begin{tabular}{lcccc}
\hline No & $\begin{array}{c}\text { Affective feelings: "Does it bother you that Jews have more money?" } \\
\text { Don't } \\
\text { know }\end{array}$ & $\begin{array}{c}\text { Yes } \\
\text { ascertained }\end{array}$ & Total \\
\hline 96.3 & 0.3 & 3.0 & 0.3 & $100 \%(985)$ \\
\hline
\end{tabular}

${ }^{a}$ Non-whites and Jews excluded from analysis. $N=1656$, of whom $59.5 \%$ (985) believe that "Jews have more money." Source: NORC survey of the United States, 1964.

Jews in the business world item is one of 11 belief items comprising the Index of Anti-Semitic Belief, the major indicator of anti-Semitism in Selznick and Steinberg's (1969) volume, The Tenacity of Prejudice. In that study, they argue that:

Not all anti-Semitic beliefs are equally unenlightened and equally pejorative. . . . But people who believe that ... Jews have too much power in the business world, not only exhibit lack of cognitive sophistication but also accept a hostile characterization.

(Selznick and Steinberg, 1969, p. 136).

A more extreme item on the power of Jews, "Do you think the Jews have too much power in the United States?" was also included in their Index of Anti-Semitic Belief, and Table 2 indicates that, among those responding positively to this item, $41.7 \%$ think that something should be done to take power away from the Jews. Although this comprises a much more substantial proportion than with the other, less general question, it still constitutes less than half of the respondents who believe that Jews have too much power in the United States. When the two power of the Jews

TABLE 2

Action Orientation toward Power of Jews of Those Who Believe that Jews Have Too Much Power in (a) the Business World and (b) the United States ${ }^{a}$

\begin{tabular}{lccccc}
\hline & \multicolumn{5}{c}{ Action orientation: "Should something be done to take } \\
power away from Jews?"
\end{tabular}

a Non-whites and Jews excluded from analysis. $N=1656$, of whom $28.6 \%$ (474) think that "Jews have too much power in the business world" and $10.9 \%$ (180) think that "Jews have too much power in the United States." Source: NORC survey of the United States, 1964. 
items are summed to form a single index (table not presented here), $43.6 \%$ of those saying "yes" to both items think that the power of the Jews should be reduced.

\section{Behavior Orientation}

Inter-ethnic attitudes are sometimes measured with questions tapping the conative dimension alone, with items asking about opinions on such issues as segregation of blacks and whites, government policies to promote racial integration, or laws restricting or prohibiting Jewish immigration, or about probable behavioral reactions to a black or a Jew trying to enter one's social club, or to an anti-Semitic or anti-black political candidate. The problem with depending on these types of questions to reflect a person's attitude toward an ethnic group is that a person's orientation toward a group in an action situation involves much more than simply his beliefs about and feelings toward the object group. The influence of extraneous factors on an act of behavior has received much attention in the attitude-behavior literature (e.g., Merton, 1949; Campbell, 1963; Rokeach, 1967; Ehrlich, 1969; Katz and Gurin, 1969), but has rarely been applied to discussions of behavior predispositions. It is not questioned that, all other things being equal, a person's behavior orientation toward a group will follow in line with his affective feelings toward that group. However, other factors that also influence a person's action orientation cannot be considered to be equal across respondents.

What Rokeach (1967) calls the respondent's "attitude toward the situation" may be as important as his feelings toward the object in shaping his behavioral predisposition toward the object. A group of respondents who share the same beliefs and feelings about an ethnic group may vary in their beliefs and feelings about other aspects of some situation or policy, and their varying behavioral predispositions will reflect their varying sensitivities to these other elements. Prothro and Grigg (1960) report a general tendency for respondents to appear to have more positive predispositions when responding to general principles of action orientation than when applying those principles to specific situations. Presumably, the application of general principles to a specific case involves an introduction of extraneous situational factors to which the respondent is sensitive.

Table 3 presents the responses of individuals of Protestant, Catholic, Jewish, other, and no religious affiliation to three items that tap the conative dimension of attitude toward Jews by asking the respondent's opinions about a hypothetical situation involving the singing of Christmas carols in a public school where there are Jewish students in a class (data from the NORC 1964 survey). Responses are broken down by religious affiliation to see whether or not the reactions of Jews differ sharply enough from those of other religious affiliations to warrant an assumption that action orientation in this situation accurately reflects attitude toward 
TABLE 3

Action Orientation toward Jews by Religion ${ }^{a}$

\begin{tabular}{lllll}
\hline \multicolumn{4}{c}{ Religion $^{b}$} \\
\cline { 2 - 4 } & Protestant & Catholic & Jewish & Other None
\end{tabular}

(a) Should public school teachers teach Christmas carols, even if some students are Jewish?

\begin{tabular}{|c|c|c|c|c|c|}
\hline No & 5.1 & 3.1 & 29.5 & 0.0 & 14.3 \\
\hline Don't know & 3.7 & 2.2 & 0.0 & 15.4 & 2.0 \\
\hline Yes (qualified) & 9.3 & 7.6 & 16.4 & 7.7 & 12.2 \\
\hline Yes (unqualified) & 81.8 & 87.1 & 54.1 & 76.9 & 71.4 \\
\hline \multicolumn{6}{|c|}{$\begin{array}{l}\text { How much would you sympathize with Jewish } \\
\text { parents who complain to principal? }\end{array}$} \\
\hline Very much & 5.2 & 2.3 & 32.8 & 0.0 & 12.2 \\
\hline Somewhat & 15.3 & 12.9 & 11.5 & 15.4 & 14.3 \\
\hline A little & 20.5 & 23.5 & 6.6 & 15.4 & 16.3 \\
\hline Don't know & 3.7 & 2.7 & 1.6 & 7.7 & 2.0 \\
\hline at all & 55.3 & 58.5 & 47.5 & 615 & ג3 \\
\hline
\end{tabular}

(c) What do you think should be done, continue singing

Christmas carols or stop singing them?

\begin{tabular}{lrrrrr} 
Stop & 5.8 & 4.5 & 29.5 & 0.0 & 12.2 \\
$\begin{array}{l}\text { Continue if Jewish } \\
\text { songs are sung }\end{array}$ & 3.5 & 2.5 & 11.5 & 15.4 & 4.1 \\
$\begin{array}{l}\text { Continue if Jewish } \\
\text { children excused }\end{array}$ & 11.0 & 11.0 & 3.3 & 7.7 & 14.3 \\
$\begin{array}{l}\text { Other } \\
\text { Continue (unqualified) }\end{array}$ & 6.4 & 6.7 & 11.5 & 7.7 & 12.2 \\
$\quad$ total sample & $(1341)$ & $(511)$ & $(61)$ & $(13)$ & (49) \\
\hline
\end{tabular}

${ }^{a}$ Total sample included in analysis; $N=1975$. Source: NORC survey of the United States, 1964.

${ }^{b}$ Each column in each section (a, b, and c) comprises $100 \%$.

Jews. Although the reactions of the Jewish respondents differ fairly substantially and consistently from those of the other respondents, still, $70 \%$ of the Jews think that the public school teacher should teach Christmas carols, even if some students are Jewish (and 54.1\% hold this opinion without qualification), $47.5 \%$ would have no sympathy at all for Jewish parents who complain to the principal about the singing of Christmas carols, and $44.3 \%$ think without qualification that the teacher should continue teaching Christmas carols after Jewish parents have complained. With such a high proportion of Jews giving the "anti-Semitic" response to these items, we must conclude (unless we care to assume very high levels of self-hate among American Jews) that respondents are considering many other factors, as well as their beliefs and feelings about Jews (such 
as their level of support for the principle of separation of church and state, and their degree of support for the authority of the school in the construction of its educational programs), when they address themselves to this hypothetical situation.

Situations may vary not only in terms of the competing stimuli offered, but also in terms of the normative or legal constraints they impose. Merton (1949) suggests that a person from a Southern milieu is less likely than a non-Southerner to question discriminatory practices, at any given level of personal affect toward blacks: When respondents have been socialized in a cultural setting that is imbued with a long history of institutionalized discrimination against an ethnic group, they are less likely to question discriminatory practices and policies, even when they have relatively positive beliefs and feelings about the group. Conversely, when the normative setting is appropriate, individuals may be more likely than individuals from other settings to express a positive action orientation toward a group even when they have negative beliefs and feelings about the group. A democratic society is supposed to encourage such a norm of tolerance, whereby individuals treat their personal beliefs and feelings about a group as irrelevant to the granting of full citizen rights to that group (Stouffer, 1955; Prothro and Grigg, 1960).

Further complicating factors in understanding behavior predispositions lie in the variance across individuals in (a) tendency to conform to normative prescriptions and (b) intensity of feelings about the ethnic group vis-à-vis other stimuli present in a given situation. Some individuals may think nothing of or even enjoy "sticking their necks out" over some issue, while others may experience great personal difficulty in saying or doing anything that would "rock the boat" and draw undue attention to themselves (Katz and Stotland, 1959, p. 455; Allport, 1962, p. 125; Hyman, 1969 , p. 25). Other things being equal, individuals with intense feelings about the racial issue should be more accurate in their translation of personal beliefs about and affect toward blacks into behavior predispositions toward blacks. As individuals sort through the various stimuli and normative expectations in a particular context, the intensity of their feelings on the race issue should be an important factor in determining what aspects of the situation are selected as being most salient in the formation of an action orientation toward blacks.

In short, situations vary in terms of both competing stimuli and normative prescriptions. Individuals vary in their susceptibility to conform and in the intensity of their feelings about the varying stimuli and norms available in different situations. Merton's (1949) typology consisting of "all-weather liberal," "fair-weather liberal," "fair-weather illiberal," and "all-weather illiberal" helps to capture these various constraints on an individual's behavior predispositions as well as the obvious constraint 
of the substance of the individual's beliefs and feelings about the ethnic group.

\section{Affect}

The literature on inter-ethnic attitudes has traditionally assigned prime conceptual importance to the affective element of a prejudiced attitude. "Ethnic prejudice is an antipathy based upon a faulty and inflexible generalization. It may be felt or expressed" (Allport, 1958, p. 10; the emphasis is mine). The use of terms like "hostile" and "irrational" in studies of inter-ethnic attitudes emphasizes the emotive aspect of the attitude. However, affect alone also gives an incomplete picture of an inter-ethnic attitude.

Although we assume that everyone with negative affect toward a group will hold more negative than positive beliefs about that group, a measure of affect alone will not tell us how many or what kinds of beliefs the respondent bases his feelings on. Conversely, a measure of the affective element alone would not allow us to distinguish between respondents who base their positive affect on a rejection of negative stereotypes about the group and those who base their positive affect on an acceptance and a positive evaluation of stereotypical (or nonstereotypical) characteristics to describe the group. Furthermore, since a person's behavioral predisposition toward an ethnic group is a function of many factors in addition to his feelings toward the group, knowledge of a person's feelings alone will give only a partial guide to his action orientation in a specific context.

The conceptual distinctiveness of the three components of an interethnic attitude not only suggests that measures of the cognitive or conative dimensions are inadequate to reflect all of the components of an inter-ethnic attitude, but, further, demotes the affective component from its conceptual position as the all-powerful crux of an inter-ethnic attitude. As Hacker (1951) points out, the emphasis on affect in the inter-ethnic attitudes literature may be somewhat misguided: Men may feel positive affect toward women, but that positive affect may be based on a set of beliefs about women's characteristics that also justify an orientation to restrict the sphere of women's activitics. The attitudes of many white slave owners toward blacks in the "old South" may similarly have involved a "benevolent" combination of positive affect with negative beliefs and action orientations for all but a narrow range of characteristics and situations.

While this discussion has been devoted to the conceptual uniqueness of each of the three components of an inter-ethnic attitude, the intention has not been to imply that they have no shared variance. Rather, the purpose has been to emphasize that the conceptual distinctions among these components are sufficient to warrant an inquiry into their empirical distinctiveness. 


\section{AN EMPIRICAL ILLUSTRATION: THE RELATION BETWEEN AFFECT AND ACTION ORIENTATIONS TOWARD BLACKS}

Both Triandis (1967, p. 245) and Fishbein (1967, p. 479) have argued the need for empirical analyses to decompose the term "attitude" into its components and assess the relationships among them, in order to test the tricomponent conceptualization of an attitude. A replicated factor analytic study of over 100 items among three student samples by Woodmansee and Cook (1967) failed to isolate cognitive, affective, and conative components, but, instead, yielded 11 content-defined dimensions, each of which comprised some cognitive, conative, and/or affective items. However, research by Ostrom (1969), using the Campbell-Fiske (1959) multitrait-multimethod matrix, did succeed in empirically isolating cognitive, affective, and conative components of attitude toward the church. In short, the evidence to date is mixed: Besides, the reliance of these studies on student samples restricts their external validity.

The following analysis is based on a probability sample of the United States (the 1968 presidential election study conducted by the Survey Research Center at the University of Michigan ${ }^{4}$ ), which provides several items measuring various aspects of attitudes toward blacks. While the survey includes no measures of beliefs about black characteristics, it has one item tapping affect toward blacks and four items tapping action orientation toward blacks in a policy context. These provide sufficient data for an analysis of part of the discussion of the preceding section.

I begin by grouping these items on a conceptual basis, with one item as an indicator of affect, two as indicators of general policy orientation toward blacks, and two as indicators of more applied policy orientation toward blacks. The representation of the conative dimension with policy orientation items directed toward the group as a whole rather than with personal action orientation items directed toward individual group members seems to be especially appropriate in this case. Personal inter-racial contact in the United States is so restricted that personal "behavior predispositions" must be extremely unrealistic for the majority of whites. ${ }^{5}$ However, restricted personal inter-racial contact would not prevent the formation of meaningful policy orientations toward blacks as a group, and, in fact, racial policy matters were a highly salient political

4 The SRC sample is an area-probability sample of the United States. It has a basic $N$ of 1557,14 of whom are wrong respondents selected accidentally, leaving an $N$ of 1543 .

${ }^{5}$ On a scalc constructed from items in the 1968 SRC survey measuring proportion of blacks perceived by the respondent in neighborhood, local grade school, junior high school, high school, work place, and shopping center, each component item was scored from $\mathbf{0}$ (for "all white") through 1 ("mostly white"), 2 ("about half and half"), and 3 ("mostly Negro") to yield a maximum possible range from 0 to 18 . For the 1366 whites measured by this scale, the mean score was 3.59 , suggesting that the average level of contact with blacks among white Americans is very low. 
issue in $1968 .{ }^{6}$ The division of the four conative items into two groups is consistent with the discussion earlier of the sensitivity of behavior predispositions to varying situational factors and the particular distinction between broad principles and specific applications of action orientation.

The items are worded and scored as follows (note that a high Temperature Toward Blacks score indicates positive feelings, while high scores on the other four items indicate a negative orientation):

\section{(1) Temperature Toward Blacks (Affect)}

"I have here a card on which there is something that looks like a thermometer. We call it a 'feeling thermometer' because it measures your feelings toward groups. Here's how it works. If you don't know too much about a group, or don't feel particularly warm or cold towards them, then you should place them in the middle, at the 50 degree mark. If you have a warm feeling toward a group, or feel favorably toward it, you would give it a score somewhere between 50 and 100 degrees depending on how warm your feeling is toward the group. On the other hand, if you don't feel very favorably toward some of these groups-if there are some you don't care for too much-then you would place them somewhere between 0 and 50 degrees."

The respondent was then asked about his "temperature" toward blacks.

\section{(2) Action Orientation (General)}

Which of these statements would you agree with:

(a) White people have a right to keep Negroes out of their neighborhoods if they want to.

(b) Negroes have a right to live wherever they can afford to, just like anybody else.

Agreement with (a) scored 4; agreement with (b) scored 0; "don't know" scored 2.

\section{(3) Action Orientation (General)}

Are you in favor of desegregation (scored 0 ), strict segregation (scored 4), or something in between (scored 2)? "Don't know" scored 2.

\section{(4) Action Orientation (Applied)}

Some people feel that if Negroes are not getting fair treatment in jobs the government in Washington should see to it that they do. Others feel that this is not the federal government's business. Have you had enough interest in this question to favor one side over the other? [If yes] How do you feel? Should the government in Washington:

(a) see to it that Negroes get fair treatment in jobs $(=0)$;

(b) other, depends $(=2)$;

(c) leave these matters to the states and local communities $(=4)$;

(d) don't know ( $=2)$;

(e) no interest $(=2)$.

\section{(5) Action Orientation (Applied)}

Some people say that the government in Washington should see to it that white and Negro children are allowed to go to the same schools. Others claim this is not the

${ }^{6}$ According to data presented by Converse et al. (1969), civil rights constituted one of the two most important issues of the 1968 Presidential Election campaign. 
government's business. Have you been concerned enough about this question to favor one side over the other? [If yes] Do you think the government in Washington should:

(a) see to it that white and Negro children go to the same schools $(=0)$;

(b) other, depends $(=2)$;

(c) stay out of this area as it is none of its business $(=4)$;

(d) don't know $(=2)$;

(e) no interest $(=2)$.

On all of these items, missing data were assigned mean values. "Don't know" responses and other responses indicating qualified opinions, ambivalence, or lack of interest were given intermediate scores on the rationale that such responses indicate neutrality where the respondent might move one way just as easily as the other.

The conative items are all constructed with equally balanced response options, a procedure that past research suggests will yield more valid items than agree-disagree statements (Jackman, 1973). I cannot report any prior research on the validity of temperature scales for measuring affect toward particular groups, but note that the phrasing of this item balances positive and negative response options equally, gives respondents a continuum that includes neutrality on which to place themselves, and presents respondents with a fairly novel context within which to express their feelings (thus discouraging a standard response set).

The next step is to examine the intercorrelations among these items to see if their pattern conforms to the theoretical expectations discussed earlier. Here we use logic similar to that suggested by Campbell and Fiske (1959), namely, that the items in the same conceptual group should correlate more highly with each other than with other items before they can be considered to have both convergent and discriminant validity. While the data do not allow us to evaluate alternative methods of measurement as well as variation in item content, this is not a serious shortcoming for two reasons. First, as noted above, the items are well constructed, with no obvious sources of systematic measurement error. Second, the essential method characteristics of all of the items appear to be highly similar (that is, content variation does not coincide with fundamentally different methods of measurement, as would be the case if one conceptual group consisted of agree-disagree statements and another comprised questions with equally balanced response options).

More problematic is the availability of only one item measuring feelings toward blacks, which prevents a direct assessment of that measure's validity. However, the correlations presented in Table 4 indicate that each item in the general action orientation and the applied action orientation groups correlates more highly with the other item in the same group than with either the items in the other group or the Temperature Toward Blacks item. ${ }^{7}$ The two general policy orientation items correlate .49 with

7 The items also attained discriminant validity vis-à-vis other items in the data set tapping such variables as political efficacy, economic satisfaction, and affective feelings toward various political groups, parties, and candidates (data not presented here). 
TABLE 4

Intercorrelations among the Items from the Temperature Toward Blacks, Segregationism, and Government Action Scales, United States

SRC Election Survey, $1968^{a}$

\begin{tabular}{llllll}
\hline & $(1)$ & $(2 \mathrm{i})$ & (2ii) & (3i) & (3ii) \\
\hline Temperature Toward Blacks (1) & 1.0 & & & & \\
Segregationism (2i) & -.284 & 1.0 & & & \\
Segregationism (2ii) & -.337 & .493 & 1.0 & & \\
Government Action (3i) & -.160 & .163 & .244 & 1.0 & \\
Government Action (3ii) & -.218 & .291 & .362 & .426 & 1.0 \\
\hline
\end{tabular}

${ }^{a}$ Non-whites excluded from the analysis; $N=1361$. Within-scale correlations are italicized.

each other, and the two applied policy orientation items correlate .43 with each other, while the inter-item correlations between groups are substantially lower. Thus, the pattern of the intercorrelations among these items conforms to theoretical expectations, which is particularly significant given the constraints of secondary data analysis, in which the choice of items is severely restricted and the data were collected without this specific purpose in mind. In analyses not presented here, the pattern of intercorrelations reported in Table 4 was successfully replicated with the same items in the 1964 and 1972 presidential election surveys, suggesting that this empirical disaggregation has considerable stability.

Given these results, the two items tapping general support for segregation are combined into a Segregationism scale, and the two items indicating support for government action to promote integration are combined into a Government Action scale. We turn now to a causal analysis of the relationships among the Temperature Toward Blacks, Segregationism, and Government Action scales to pursue further some of the empirical implications of the earlier theoretical discussion.

Figure 1 presents a model in which feelings of warmth (or coldness) toward blacks lead to variation in support for segregation. Both of these scales, in turn, lead to opinions about government intervention to bring about integration in schools and employment. Thus, consistent with the literature discussed earlier in this paper, the model assumes that affect leads first to more general conative opinions or "principles" of policy orientation toward blacks and that affect then has both a direct and an indirect effect, through general support for segregation, on more specific opinions about government intervention to promote civil rights for blacks. The estimates for the model in Fig. 1 indicate moderate relationships among the three scales. Correction for probable attenuation of the relationships due to unreliability in the scales does not alter this conclusion. ${ }^{8}$

${ }^{8}$ The alpha coefficients for the Segregationism and Government Action scales are .632 and .608 , respectively. Assuming a reliability of .5 for the Temperature Toward Blacks 

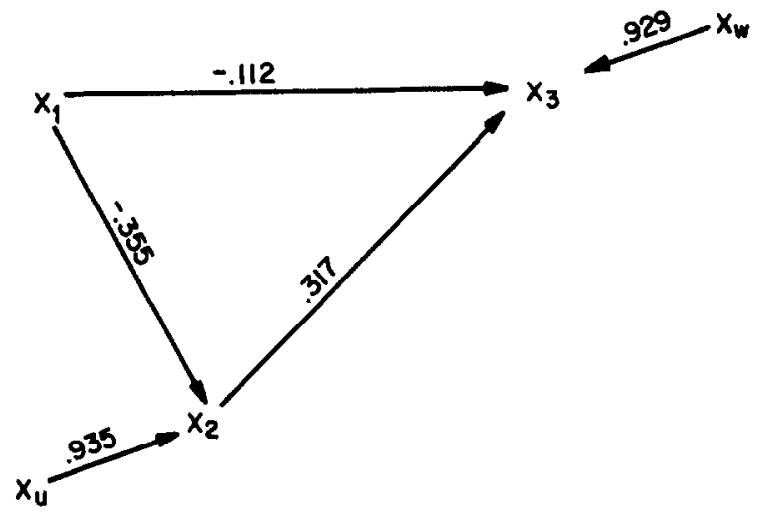

$x_{1}$ Temperature Toward Blacks

$X_{2}$ Segregationism scole

$X_{3}$ Government Action scale

FIG. 1. Path model of the relationship among three indicators of attitude toward blacks (SRC election survey, 1968; non-whites were excluded from analysis; $N=1361$ ). All paths are significant beyond .05 .

Even within the conative dimension, a move from general principles to more specific policies produces a sharp difference in responses (the zero-order correlation between the two action orientation scales is .356). In accord with work by Prothro and Grigg (1960) on support for general statements and for specific applications of fundamental principles of democracy, the mean score on the more general of our action orientation scales is more positive than on the more specific scale. Both scales range from 0 to 8 , with lower scores being more positive; the mean score for whites on the Segregationism scale is 2.9 , while, on the Government Action scale, it is 4.6. The zero-order relationship between affect and action orientation is stronger for more general principles than it is for more specific policy opinions: The correlation of Temperature Toward Blacks with the Segregationism scale is - .355 (note that this is as high as the correlation between general and applied policy orientation), while Temperature correlates - .244 with the Government Action scale. This result is consistent with our theoretical expectation that, as one becomes further removed from general principles and closer to practical applica-

scale, the "corrected" correlations between Temperature Toward Blacks and Segregationism, Temperature Toward Blacks and the Government Action scale, and the Segregationism and Government Action scales are estimated as being $-.569,-.412$, and .566 , respectively [formulas are given in Bohrnstedt (1970, pp. 84 and 89); see Novick and Lewis (1967) and Lord and Novick (1968) for discussions of the assumptions necessary to make Cronbach's alpha a "true" lower-bound estimate of the reliability of a scale]. 
tions, extraneous environmental factors interfere increasingly with the relationship between affect and action orientation. Further, Fig. 1 indicates that approximately half of the effect of Temperature Toward Blacks on responses to the Government Action scale is mediated by degree of support for segregation $\left[r_{13}=p_{31}+p_{32} p_{21}=(-.112)+(-.113)\right]$.

The discussion earlier in this paper of the action orientation dimension suggested that the normative setting, competing stimuli, the respondent's tendency to conform, and the intensity of his feelings about the racial issue are all important influences on the relationship between affect and action orientation toward blacks. We are able to carry out an empirical examination of the impact of two of these factors, the normative setting and attitudinal intensity, with data from the SRC survey.

The first variable from the SRC data that is relevant to our discussion of the translation of affect into action orientation comes from a question asking in which region of the country the respondent was raised. By separating Southern-raised respondents from non-Southerners, we can examine the impact of different normative traditions in race relations on the relationship between affect and action orientation toward blacks. A measure reflecting Southern upbringing rather than current residence in the South was chosen on the presumption that the former is more likely to indicate a prolonged exposure to a Southern milieu and at a specially formative period in the individual's life. ${ }^{9}$ Because of the South's historical background of more explicit institutional legitimation of discriminatory practices, whites socialized in a Southern milieu should be less likely than non-Southerners with comparable feelings toward blacks to question segregationist policies or actions toward blacks (Merton, 1949). This approach implies that the slope of Segregationism regressed on Temperature Toward Blacks should be the same for Southerners and non-Southerners, but the intercept for Southerners should be higher, making Southerners more likely than non-Southerners to support segregationist policies at any given point on the Temperature scale.

The following equation allows a test of Merton's argument.

$$
X_{2}=a+b_{1} X_{1}+b_{2} X_{4}+b_{3}\left(X_{1} X_{4}\right)+e,
$$

where $X_{2}$ is the Segregationism score, $X_{1}$ is Temperature Toward Blacks, and $X_{4}$ is a dummy variable scored 1 for respondents raised in the South and 0 otherwise. Note that this model permits both the intercept and the slope for Southerners to differ from those for non-Southerners.

The parameter estimates for this equation (see Fig. 2) indicate that normative environment has a substantial influence on the relationship between feelings and action orientation toward blacks. As suggested by

9 According to data presented by Converse et al. $(1969$, p. 1103), only a small proportion of whites raised in the South resided outside the South at the time of the survey (approximately $16 \%$ ). 


$$
x_{2}=4.75-(.037) x_{1}+(2.967) x_{4}-(.020)\left(x_{1} x_{4}\right)
$$

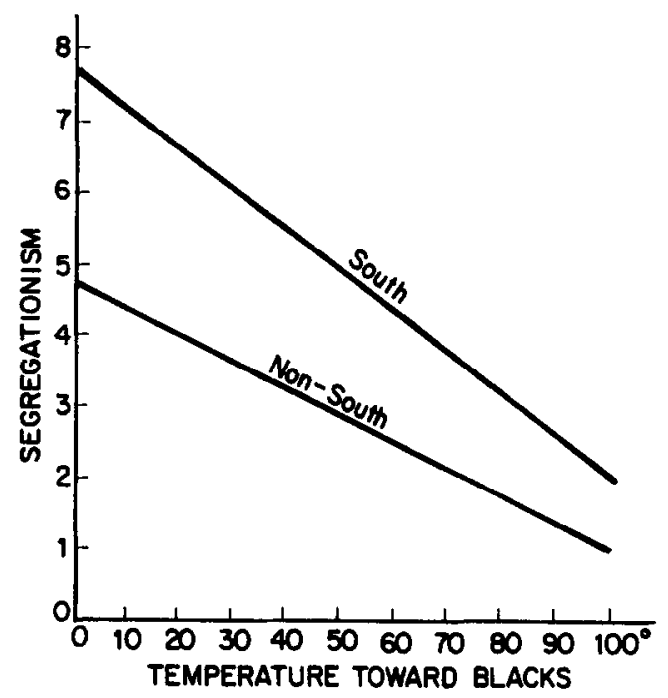

FIG. 2. Relationship hetween Temperature Toward Blacks and Segregationism, for Southern- and non-Southern-raised (SRC survey, 1968; non-whites were excluded from analysis).

Merton (1949), Southerners are more likely to express support for segregation than non-Southerners with comparable feelings toward blacks. However, this difference between Southerners and non-Southerners is considerably greater among respondents with negative feelings toward blacks than among those with positive feelings. Thus, these estimates suggest that socialization in an overtly discriminatory environment encourages a discriminatory action orientation, whatever the respondent's personal feelings toward blacks, but the effect of the negative environment is more pronounced when the respondent's feelings are consistent with it. While Temperature Toward Blacks alone accounts for only $12.6 \%$ of the variance in Segregationism, Eq. (1) above explains $21.0 \%$ of the variance in the latter measure.

Two similar equations were specified, with the Government Action scale as a function of (a) Temperature Toward Blacks, Segregationism, Southern upbringing, and the Temperature-Southern interaction term, and (b) Temperature Toward Blacks, Segregationism, Southern upbringing, and a Segregationism-Southern interaction term. In both cases, the estimates of the main and interaction effects associated with the South were not statistically significant $(p>.05)$. A simpler equation excluding the interaction term yielded a small but statistically significant estimated coefficient for the South; however, this equation increased the $R^{2}$ from 13.8 to only $14.2 \%$. Thus, I will represent the impact of Southern upbring- 
ing on the Government Action score as indirect only, through its influence on support for segregationist principles.

The second variable that is relevant to the discussion of action orientation earlier in the paper is a question that followed the first item of the Segregationism scale, "Do you feel strongly about your position on this question [of housing integration] or not too strongly?" This item, which is the only measure of attitudinal intensity in the SRC survey, is used here as an approximate indicator of how strongly the respondent feels on the race issue. A more complete measure would include more than one "intensity" follow-up and would also include measures of the intensity with which the respondent holds other competing beliefs, feelings, and action orientations that are relevant to a given hypothetical situation. However, the inadequacies of the single item make it a conservative indicator of relative intensity of action orientation toward blacks, since it is more unreliable than a multiple-item indicator would be and since it fails to consider the possibility that some people may feel strongly about segregation because they have personalities that lead them to feel strongly about most issues rather than because of special salience of the race issue. The conservatism of our indicator makes it liable to lead to a "false" rejection of the hypothesis under examination rather than to its false acceptance, and, thus, we can be less hesitant about using it. Approximately $56 \%$ of the white respondents indicated that they felt "strongly" on the intensity item, and this item is uncorrelated with any of the three scales tapping aspects of attitude toward blacks.

Recall that the earlier discussion implies that respondents who feel strongly about the race issue should translate their feelings toward blacks into action orientation toward blacks more accurately than should respondents who do not feel strongly about the race issue. This suggests the following model.

$$
X_{2}=a+b_{1} X_{1}+b_{2} X_{5}+b_{3}\left(X_{1} X_{5}\right)+e,
$$

where the first three terms are defined as in Eq. (1), and $X_{5}$ is a dummy variable for attitudinal Intensity, scored 1 for those who feel strongly and 0 otherwise.

The estimates for Eq. (2) (shown in Fig. 3) indicate that both the intercepts and the slopes for the two levels of attitudinal intensity differ sharply, and in the hypothesized direction. The slope for those who did not express strong feelings on the issue stays close to the center of the Segregationism scale and is not significantly different from zero, while the slope for those who do feel strongly is very steep and spans almost the entire range of the dependent variable. Furthermore, Eq. (2) explains $16.6 \%$ of the variance in Segregationism, whereas Temperature alone explained $12.6 \%$ of the variance in Segregationism. 


$$
x_{2}=3.455-(.008)^{*} x_{1}+(3.303) x_{5}-(.055)\left(x_{1} x_{5}\right)
$$

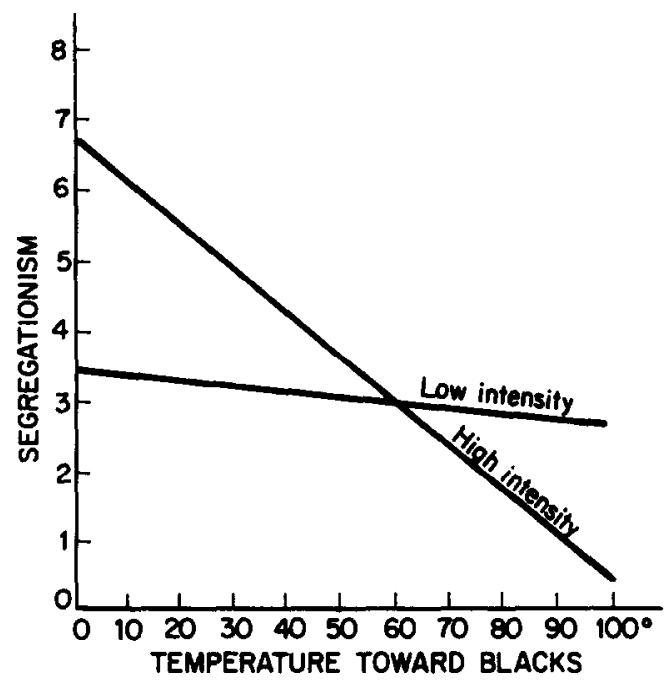

FIG. 3. Relationship between Temperature Toward Blacks and Segregationism for high and low intensity of opinion on racial issue (SRC survey, 1968; non-whites excluded from analysis). The starred $\left(^{*}\right)$ coefficient is not statistically significant $(p>.05)$.

The remainder of the basic model in Fig. 1 is similarly elaborated by specifying two alternative equations: (a) the Government Action scale as a function of Segregationism, Temperature Toward Blacks, attitudinal Intensity, and the Temperature-Intensity interaction term, and (b) the Government Action scale as a function of Segregationism, Temperature Toward Blacks, Intensity, and a Segregationism-Intensity interaction term. In the first, the main effect for Intensity was statistically insignificant $(p>.05)$, and, in the second, the interaction term was statistically insignificant. Given the inconsistency in these estimates and the small increments in $R^{2}$ [from 13.8 to $14.6 \%$ in Eq. (a) and to $14.3 \%$ in Eq. (b)], attitudinal Intensity is represented as having only an indirect effect on the Government Action scale through its influence on the translation of feelings toward blacks into support for segregation.

Figure 4 presents the estimates for a model that combines Eqs. (2) and (3):

$$
X_{2}=a+b_{1} X_{1}+b_{2} X_{4}+b_{3}\left(X_{1} X_{4}\right)+b_{4} X_{5}+b_{5}\left(X_{1} X_{5}\right)+e,
$$

where all terms are defined as before. This model allows us to present a finer breakdown of factors influencing the relationship between affect and policy orientation about segregation, and it yields an $R^{2}$ of $24.3 \%$. These estimates are built into the path model in Fig. 5, which constitutes an elaboration of the model presented earlier in Fig. 1. In Fig. 5, $p_{21}$ gives the 


$$
\begin{aligned}
x_{2}=2.78-(.004)^{*} x_{1} & +(2.842) x_{4}-(.019)\left(x_{1} x_{4}\right) \\
& +(2.980) x_{5}-(.050)\left(x_{1} x_{5}\right)
\end{aligned}
$$

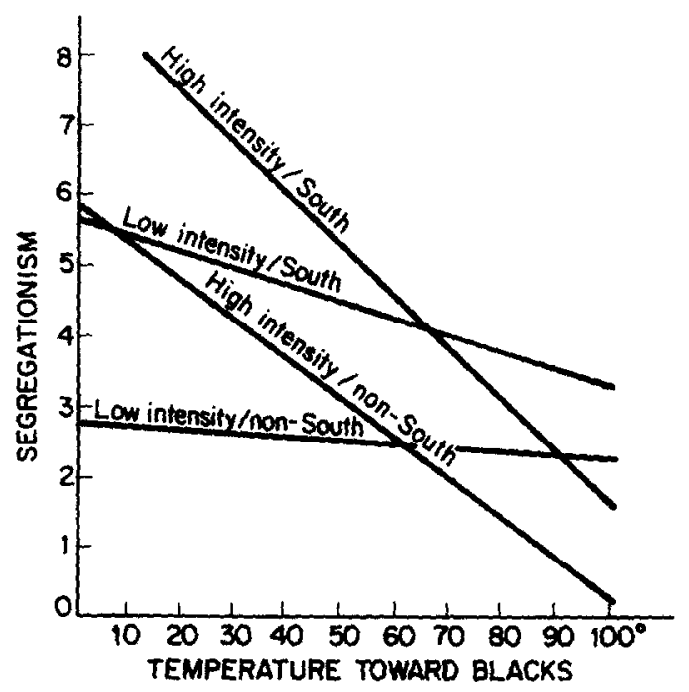

Fig. 4. Relationship between Temperature Toward Blacks and Segregationism for high and low intensity of opinion, Southern- and non-Southern-raised (SRC survey, 1968; nonwhites were excluded from analysis). The starred $\left(^{*}\right)$ coefficient is not statistically significant $(p>.05)$.

standardized slope of Segregationism on Temperature Toward Blacks for non-Southerners who did not express strong feelings on the race issue, $p_{24}$ and $p_{25}$ give the net adjustments to the intercept in Segregationism for Southern-raised and high Intensity respondents, respectively (in a standardized system these are adjustments from zero, expressed in standard deviation units), and $p_{26}$ and $p_{27}$ give the net adjustments to the slope of Segregationism on Temperature Toward Blacks for Southernraised and high Intensity respondents, respectively (thus, the standardized slope for high Intensity non-Southerners is $[-.030-.664]=$ -.694 , while, for high Intensity Southerners, it is $[-.030-.664-.190]=$ $-.884)$.

The final model suggests that attitudinal intensity and environmental norms both have a substantial impact on the way in which feelings toward blacks are translated into general policy orientation, and, through their impact on Segregationism, they also have an indirect effect on opinions about government intervention to enforce black civil rights. ${ }^{10}$ This exploratory analysis points to the utility of collecting more exhaustive data on all three components of an inter-ethnic attitude, their intensity, and rele-

\footnotetext{
${ }^{10}$ For discussion and analysis of the impact of these attitudinal components on reported
} behavior, see Jackman (1976). 


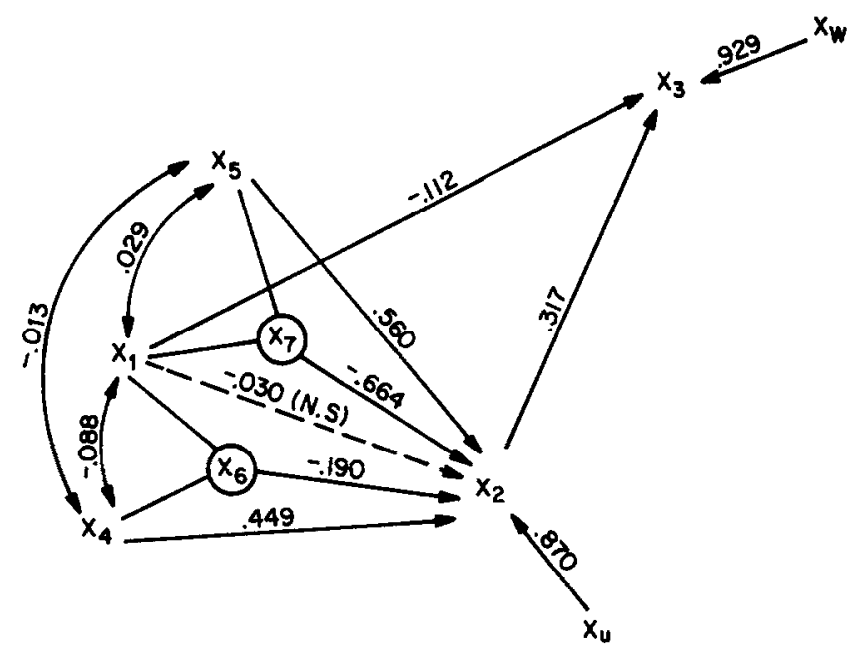

$x_{1}$ Temperoture Toword Blacks

$x_{2}$ Segregationism scale

$x_{3}$ Government Action scale

$$
\begin{aligned}
& x_{4} \text { Southern -raised } \\
& x_{5} \text { Intensity of opinion } \\
& x_{6} \text { Temperature } x \text { South } \\
& x_{7} \text { Temperature } x \text { Intensity }
\end{aligned}
$$

FIG. 5. Final model of relationship between Temperature Toward Blacks and action orientations (SRC survey, 1968; non-whites excluded from analysis; $N=1361$ ). All paths are statistically significant beyond .05 unless otherwise indicated.

vant environmental norms, as well as on other potentially influential factors, such as the individual's tendency to conform to both informal norms and formal sanctions and the substance and intensity of his attitudes on other elements in his environment that impinge on the ethnic issue.

\section{DISCUSSION}

By way of a conceptual and partial empirical decomposition of an inter-ethnic attitude, this study has suggested that the "prejudicetolerance" continuum be abandoned in favor of terms that reflect the complexities of a substantive problem involving beliefs and feelings along with action orientations that may vary considerably from one context to another. The general term "prejudice" blurs the distinctions among the various elements of an attitude, obscures questions about factors influencing the structure of an inter-ethnic attitude, and leads to mixed and often confusing results when different empirical studies use measures of quite different attitudinal elements to represent the same general concept.

Empirical recognition of the distinct elements that make up an attitude toward an ethnic group also allows us to restrict use of the term "tolerance" to its correct specific meaning rather than using it as a general 
attribute of someone who is not "prejudiced." The term "tolerance," as it has developed in the political sociology literature, refers to a condition by which the individual perceives that some group has customs, values, or interests that are different from his own and unattractive to him, but does not allow his personal dislikes to interfere with his general principles of civil rights. That the granting of full citizen rights should be completely independent of personal likes and dislikes is an important requirement for a political system that aims to offer its citizens both clear political choices and a stable framework within which to make those choices.

While many studies of prejudice have assumed few (if any) real group differences, democratic theorists have assumed that society is composed of groups (e.g., political partisans) with differing interests and opposed policy preferences. As a result, they have been concerned with adherence to the "rules of the game" which allow such groups to coexist with one another peacefully, even in the presence of substantial group differences. A classic use of the term "tolerance" in political sociology is Stouffer's (1955) Communism, Conformity, and Civil Liberties, in which it is used in reference to the issue of civil liberties for political and religious nonconformists. The key democratic principles of majority rule (which requires that political minorities abide by the rule of the majority) and minority rights (which requires that the ruling majority grant political minorities full citizen rights) specify that no group should attempt to infringe on the freedom of speech or civil liberties of political opponents. The attitude structure clearly implied by these principles is a specific "tolerant" combination of negative beliefs about and feelings toward a group with a positive behavior predisposition toward the group.

However, paralleling the gap between the conceptualization and measurement of prejudice found in many empirical studies of inter-ethnic attitudes, empirical studies of tolerance for minorities in political sociology have relied on survey items tapping the action orientation dimension alone (for example, "Should an admitted Communist be put in jail, or not?"; "Should he [an accused Communist] be allowed to make a speech in your community, or not?"), with the respondent's negative evaluation of the object group remaining an implicit assumption. The problem here is that many people who have a positive action orientation toward some group may have low norms of tolerance, but may believe that the group's interests are congruent with their own and/or they may personally find the group's perceived characteristics attractive. Other individuals with a positive action orientation may personally dislike the group because of their perceptions of its characteristics, but strong norms of tolerance prevent them from translating personal beliefs and feelings into negative behavioral predispositions. The extremity, salience, and intensity of personal dislike for a group, as well as the nature and strength of prevailing norms of behavior toward the group, may all influence the level of toler- 
ance for that group. For example, Fig. 4 suggests that both discriminatory environmental norms and intense feelings on the race issue make it more difficult for individuals with cold feelings toward blacks to sustain a tolerant position toward blacks on the question of racial segregation.

In short, while the primary theoretical concern of the literature on inter-ethnic attitudes has been with what makes one group like another, democratic theory in political sociology has been largely concerned with what makes one group tolerate another (disliked) group. The empirical decomposition of an inter-ethnic attitude and the conceptual isolation of tolerance as a specific combination of attitudinal components suggest the utility of applying the concept of tolerance to the study of attitudes toward ethnic groups, as well as toward political groups. Whether or not the cultures of different ethnic groups in the United States stress incompatible values remains an empirical question that cannot be answered here. However, many citizens certainly believe that other ethnic groups do differ significantly from their own. A shift in emphasis in the ethnic attitudes literature from prime concern with intergroup feelings (however measured) to equal concern with intergroup tolerance would broaden the scope of the literature from both a theoretical and a policy perspective, increasing both its sensitivity to and its relevance for the general problem of multigroup coexistence in a democratic society.

Thus, abandonment of the prejudice-tolerance continuum for a more precise set of terms that are treated as empirically salient would encourage a rigorous probing of both inter-ethnic attitudes and intergroup attitudes among other groups differing from one another on any criteria. Empirical recognition and exploration of the complexity of inter-ethnic attitudes in mass publics with more exhaustive data files than those available to the present study seem to be necessary precursors to the development of compelling theories to explain and policies to minimize negative beliefs, feelings, and/or action orientations toward groups that differ from the individual on ethnic, political, sexual, socioeconomic, or any other criteria.

\section{REFERENCES}

Allport, G. W. (1958), The Nature of Prejudice, Anchor Books, New York.

Allport, G. W. (1962), "Prejudice: Is it societal or personal?" Journal of Social Issues 18, 120-134.

Bettelheim, B., and Janowitz, M. (1965), "Ethnic tolerance: A function of social and personal control," in Basic Studies in Social Psychology (H. Proshansky and B. Seidenberg, Eds.), pp. 685-693, Holt, Rinehart, and Winston, New York.

Bohrnstedt, G. W. (1970), "Reliability and validity assessment in attitude measurement," in Attitude Measurement (G. F. Summers, Ed.), pp. 80-99, Rand McNally, Chicago.

Brigham, J. C. (1971), “Ethnic stereotypes," Psychological Bulletin 76, 15-38.

Campbell, D. T. (1963), "Social attitudes and other acquired behavioral predispositions," in Psychology: A Study of a Science (S. Koch, Ed.), Vol. 6, pp. 94-172, McGraw-Hill, New York. 
Campbell, D. T., and Fiske, D. W. (1959), "Convergent and discriminant validation by the multitrait-multimethod matrix." Psychological Bulletin 56, 81-105.

Converse, P. E., Miller, W. E., Rusk, J. A., and Wolfe, A. C. (1969), "Continuity and change in American politics: Parties and issues in the 1968 election." American Political Science Review 68, 1083-1105.

Cook, S. W., and Seltiz, C. (1964), "A multiple-indicator approach to attitude measurement," Psychological Bulletin 62, 36-55.

Doob, L. W. (1967), "The behavior of attitudes," in Readings in Attitude Theory and Measurement (M. Fishbein, Ed.), pp. 42-50, Wiley, New York.

Ehrlich, H. J. (1969), "Attiludes, behavior, and the intervening variables," American Sociologist 4, 29-35.

Fishbein, M. (1967), "Attitude and the prediction of behavior," in Readings in Attitude Theory and Measurement (M. Fishbein, Ed.), pp. 477-492, Wiley, New York.

Frenkel-Brunswik, E., Levinson, D. J., and Sanford, R. N. (1965), "The authoritarian personality. " in Basic Studies in Social Psychology (H. Proshansky and B. Seidenberg, Eds.), pp. 670-679, Holt, Rinehart, and Winston, New York.

Greenwald, A. G. (1968). "On defining attitude and attitude theory," in Psychological Foundations of Attitudes (A. G. Greenwald, T. C. Brock, and T. M. Ostrom, Eds.), pp. 361-388, Academic Press, New York.

Hacker, H. M. (1951), "Women as a minority group," Social Forces 30, 60-69.

Harding, J., Proshansky, H., Kutner, B., and Chein, I. (1954), "Prejudice and ethnic relations," in The Handbook of Social Psychology (G. Lindzey, Ed.), Vol. 2, pp. 1021-1061, Addison-Wesley, Cambridge, Mass.

Harding, J., Proshansky, H., Kutner, B., and Chein, I. (1968), "Prejudice and ethnic relations," in The Handbook of Social Psychology (G. Lindzey and E. Aronson, Eds.), 2nd ed., Vol. 5, pp. 1-76.

Hyman, H. (1969), "Social psychology and race relations." in Race and the Social Sciences (I. Katz and P. Gurin, Eds.), pp. 3-48, Basic Books, New York.

Inkeles, A., and Levinson, D. J. (1968), "National character: The study of modal personality and sociocultural systems," in The Handbook of Social Psychology (G. Lindzey and E. Aronson, Eds.), 2nd ed., Vol. 4, pp. 418-506, Addison-Wesley, Reading, Mass.

Jackman, M. R. (1973), "Education and prejudice or education and response set?" American Sociological Review 38, 327-339.

Jackman, M. R. (1976), "The relation between verbal attitude and overt behavior: A public opinion application." Social Forces 54, 646-668.

Jones, E. E., and Gerard, H. B. (1967), Foundations of Social Psychology, Wiley, New York.

Katz, D., and Braly, K. W. (1947), "Verbal stereotypes and racial prejudice." in Readings in Social Psychology (T. M. Newcomb and E. L. Hartley, Eds.), pp. 204-210, Holt, New York.

Katz, D., and Stotland, E. (1959), "A preliminary statement to a theory of attitude structure and change," in Psychology: a Study of a Science (S. Koch, Ed.), Vol. 3, pp. 423-475, McGraw-Hill, New York.

Katz, I., and Gurin, P. (1969), "Race relations and the social sciences: Overview and further discussion." in Race and the Social Sciences (I. Katz and P. Gurin, Eds.), pp. 342-378, Basic Books, New York.

Kay, L. W. (1947), "Frame of reference in 'pro' and 'anti' evaluations of test items," Journal of Social Psychology 25, 63-68.

Krech, D., Crutchfield, R. S., and Ballachey, E. L. (1962), Individual in Society, McGraw-Hill, New York. 
Lord, F. M., and Novick, M. R. (1968), Statistical Theories of Mental Test Scores, Addison-Wesley, Reading, Mass.

Mackie, M. (1973), "Arriving at 'truth' by definition: The case of stereotype inaccuracy," Social Problems 20, 431-447.

Merton, R. K. (1949), "Discrimination and the American creed," in Discrimination and National Welfare (R. M. McIver, Ed.), pp. 99-126, Kennikat Press, Port Washington. N. Y.

Middleton, R. (1976), "Regional differences in prejudice," American Sociological Review 41, 94-117.

Novick, M. R., and Lewis, C. (1967), "Coefficient alpha and the reliability of composite measurements," Psychometrika 32, 1-13.

Ostrom, T. M. (1969), "The relationship between the affective, behavioral, and cognitive components of attitude," Journal of Experimental Social Psychology 5, 12-30.

Prothro, J. W., and Grigg, C. M. (1960), "Fundamental principles of democracy: Bases of agreement and disagreement," Journal of Politics 22, 276-294.

Robinson, J. P., Rusk, J. G., and Head, K. B. (1968), Measures of Political Attitudes, Institute for Social Research, Ann Arbor, Mich.

Rokeach, M. (1967), "Attitude change and behavior change," Public Opinion Quarterly 30, $529-550$.

Rokeach, M. (1968), Beliefs, Attitudes, and Values, Jossey-Bass, San Francisco.

Rosenberg, M. J. (1956), "Cognitive structure and attitudinal affect," Journal of Abnormal and Social Psychology 53, 367-372.

Schuman, H., and Harding, J. (1964), "Prejudice and the norm of rationality," Sociometry 27, 353-371.

Selznick, G., and Steinberg, S. (1969), The Tenacity of Prejudice: Anti-Semitism in Contemporary America, Harper, New York.

Stouffer, S. A. (1955), Communism, Conformity and Civil Liberties, Doubleday, New York.

Sudman, S. (1966), "Probability sampling with quotas," Journal of the American Statistical Association 61, 749-771.

Summers, G. F. (1970), Attitude Measurement, Rand McNally, Chicago.

Triandis, H. C. (1967), "Toward an analysis of the components of interpersonal attitudes," in Attitude, Ego-Involvement, and Change (C. W. Sherif and M. Sherif, Eds.), pp. 227-270, Wiley, New York.

Woodmansee, J. J., and Cook, S. W. (1967), "Dimensions of verbal racial attitudes: Their identification and measurement," Journal of Personality and Social Psychology 7, 240-250. 